\title{
Contraceptive use and associated factors among women seeking induced abortion in Debre Marko's town, Northwest Ethiopia: a cross-sectional study
}

\author{
Lebeza Alemu ${ }^{1 *}$, , Yeshambel Agmus Ambelie ${ }^{2}$ and Muluken Azage $^{3}$
}

\begin{abstract}
Background: Contraceptive utilization is a practice that helps individuals or couples to avoid unwanted pregnancy. Even though there is the widespread availability of contraceptives, induced abortion remains an alarming public health problem in Ethiopia. Nationally, more than a third (35\%) of women seeking an induced abortion service had a previous history of abortion. Therefore, this study aimed to assess the history of contraceptive use and identify associated factors among women seeking an induced abortion service in Debre Marko's town, Ethiopia.

Methods: An institutional-based cross-sectional study was conducted from March 15 to May 15, 2019. The sample size was 416 and each health institution was proportionally allocated based on the previous 2 months of patient flow. Systematic random sampling was used to select the study participants. A structured questionnaire was used to collect the data. Data were entered by EPI-data and analyzed using SPSS version 23. Bivariate and multivariable logistic regression analyses were carried out. Model fitness was assured.

Results: The proportion of contraceptive use within the last 6 months before pregnancy was $41.3 \%$ among women seeking an induced abortion. Women who had good knowledge about contraceptives (AOR $=3.9 ; 95 \% \mathrm{Cl}: 2.36$, 6.54), women who had a positive attitude about contraceptives ( $\mathrm{AOR}=; 95 \% \mathrm{Cl}: 1.02$, 2.56), women who had living children $(\mathrm{AOR}=2.1 ; 95 \% \mathrm{Cl} ; 1.04,4.11)$, women who had frequent sexual practice $(\mathrm{AOR}=2.5 ; 95 \% \mathrm{Cl} ; 1.53,4.21)$ and women discussed with their sexual partners about contraceptives (AOR $=1.9 ; 95 \% \mathrm{Cl}: 1.18,3.18)$ were increase the odds of contraceptive use among women seeking an induced abortion.

Conclusion: Contraceptive use among women seeking an induced abortion was low despite the expected national goal of 55\% contraceptive use in 2020. Having good knowledge and having a positive attitude on contraceptives, and having a discussion on contraceptives with sexual partner were increase the odds of contraceptive use. The intervention should focus on abortion seeking women to achieve their contraceptive needs and encourage sexual partner discussion about contraceptives to improve joint partner collective decision-making.
\end{abstract}

Keywords: Contraceptive, Use, Factors, Induced abortion, Ethiopia

\footnotetext{
*Correspondence: lebezaa@gmail.com

'Department of Midwifery, College of Health Sciences, Woldia University, Woldia, Ethiopia

Full list of author information is available at the end of the article
}

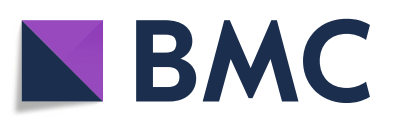

(- The Author(s). 2020 Open Access This article is licensed under a Creative Commons Attribution 4.0 International License, which permits use, sharing, adaptation, distribution and reproduction in any medium or format, as long as you give appropriate credit to the original author(s) and the source, provide a link to the Creative Commons licence, and indicate if changes were made. The images or other third party material in this article are included in the article's Creative Commons licence, unless indicated otherwise in a credit line to the material. If material is not included in the article's Creative Commons licence and your intended use is not permitted by statutory regulation or exceeds the permitted use, you will need to obtain permission directly from the copyright holder. To view a copy of this licence, visit http://creativecommons.org/licenses/by/4.0/. The Creative Commons Public Domain Dedication waiver (http://creativecommons.org/publicdomain/zero/1.0/) applies to the data made available in this article, unless otherwise stated in a credit line to the data. 


\section{Plain English summary}

Contraceptive utilization is practices that help individuals to avoid unwanted pregnancy to attain their desired children as their plan, and available methods of contraception should be customized to individual needs with a range of options. Despite widespread availability and awareness about family planning service induced abortion remains an alarming global public health problem due to poor contraceptive utilization. Therefore, this study aimed to assess the history of contraceptive use and identify associated factors among women seeking induced abortion since it is not well addressed in the study area.

All health institutions which provide legal abortion service in the study area were included. The sample size in each health institution was proportionally allocated based on the previous 2 months of patient flow, and systematically select the study participants.

The proportion of contraceptive use within the last 6 months before pregnancy was 41.3\% among women seeking an induced abortion which is low despite the expected national goal of $55 \%$ contraceptive utilization in 2020. Having good knowledge and having a positive attitude about contraceptives; and having a discussion on contraceptives with a sexual partner were factors associated with contraceptive utilization. The intervention should focus on abortion seeking women to achieve their contraceptive needs.

\section{Background}

Contraceptive use is a practice that helps individuals or couples to avoid unwanted pregnancy to attain their desired children as their plan, and available methods of contraception should be customized to individual needs with a range of options that are acceptable to all [1].

Nowadays, more attention is given on contraceptive use for multiple benefits as it prevents unintended pregnancies, which in turn reduces unsafe abortion and slows unsustainable population growth that affects the environment [2].

Worldwide in 2017, $63 \%$ of reproductive-aged women were using some form of contraception; and $58 \%$ of married or in-union reproductive-aged women were using a modern method of family planning, which comprises $92 \%$ of all contraceptive users [3].

The National Reproductive Health Strategy of Ethiopia emphasizes family planning to reduce unwanted pregnancies and enable individuals to achieve their desired family size by increasing access to and utilization of quality family planning services through building health infrastructure and the introduction of the health extension package [4].

Despite widespread availability and awareness about family planning service induced abortion remains an alarming global public health problem due to poor contraceptive utilization which is a personal and socioeconomic challenge for individuals, families, and society [5].

An estimated 620,300 induced abortions were done in Ethiopia in 2014. Between 2008 and 2014, the rate of abortions occurring in health facilities increases substantially from 27 to $53 \%$ [6]. The national figure of women receiving treatment due to complications of abortion was nearly doubled between 2008 and 2014, rising from 52,600 to 103,600 in Ethiopia [7].

Unintended pregnancy can be addressed by increasing availability and accessibility of modern contraceptives which in turn reduces the incidence of abortion with its related maternal death [8]. Despite many improvements, the non-use of contraceptives among women who wish to avoid pregnancy continues, which leads to unintended pregnancy and causing about 13\% of abortions in Ethiopia [7].

Even though there is the widespread availability of contraceptives, induced abortion remains public health problem in Ethiopia. Nationally, more than a third of women seeking induced an abortion (35\%) had had a previous history of abortion [9]. Therefore, this study aimed to assess the history of contraceptive use and identify associated factors among women seeking an induced abortion in Debre Marko's town, Northwest Ethiopia.

\section{Materials and methods Study settings}

An institution-based cross-sectional study was conducted from March 15 to May 15, 2019, among women seeking an induced abortion in Debre Marko's town which is located at $300 \mathrm{kms}$ from Addis Ababa, capital city of Ethiopia. The town has one governmental referral hospital, 3 health centers, and two non-governmental organizations (NGO) clinics that give legal abortion services at the time of study period. The study population was women seeking an induced abortion services in the selected health institutions within the study period. Women having induced abortion due to obstetrical reasons were excluded from the study.

\section{Definitions}

History of contraceptive use: use of any contraceptive method regularly with in the last 6 months before the current pregnancy time of conception.

Induced abortion refers to deliberate intervention to terminate the pregnancy.

Good knowledgeable: Refers study participants who answered $\geq 72 \%$ (mean score) of nine contraceptives knowledge questions. 
Poor knowledgeable: Refers study participants who answered $<72 \%$ (mean score) of nine contraceptives knowledge questions.

Positive attitude: Refers study participants who answered $\geq 70 \%$ (mean score) of nine contraceptives attitude questions.

Negative attitude: Refers study participants who answered $<70 \%$ (mean score) of nine contraceptives attitude questions.

Bad history of contraceptives: A women who an experience of failure of contraceptive methods and/or got bad side effects with in the last 1 year before index pregnancy.

Accessibility: if the family planning service delivery center reached within $2 \mathrm{~h}(30 \mathrm{~km})$ on foot was considered as access to family planning [10].

\section{Sample size determination and sampling procedures}

EPI-info software was used to calculate the sample size using single proportion population formula by considering the following assumptions: $\mathrm{p}$ - contraceptive practice among women seeking abortion $(p=56.6 \%)$ [11]; margin of error $(5 \%)$ and $95 \% \mathrm{CI}\left(\mathrm{z}_{1 / 2}=1.96\right)$. The final sample size was 416 by considering $10 \%$ non- response rate.

All health institutions which provide legal abortion service in the study area were included. The sample size for each health institution was determined proportionally based on the previous 2 months of clients flow. Systematic random sampling was used to select the study participants (Fig. 1). The $\mathrm{k}^{\text {th }}$ interval of systematic sampling was determined by dividing the previous 2 months client flow with the required sample size from each health institutions.

\section{Data collection instruments and procedures}

Interviewer administered questionnaire was used to collect the data. The questionnaires initially prepared in English and translated to Amharic and again back to English to check the consistency. The questionnaire constitutes socio-demographic variables, reproductive and sexual characteristics, health institution accessibility, knowledge and attitude questions on contraceptive and contraceptive use question. The questionnaire was filled by the health professionals who were working in the same health institution out of maternal and child health room. One BSc Midwife was assigned as a supervisor who supervises the data collection throughout the process in each health institution.

Data quality was assured using pre-testing and training of data collectors and supervisors. The topics of the training were data confidentiality, responders' right, informed consent, the objective of the study, on the techniques of the interview and filling the questionnaire.

\section{Data analysis}

Data were entered using EPI data and analyzed using SPSS version 23. Descriptive statistics were used to describe the data. Bivariate analysis was employed to examine the association between dependent and independent variables. Finally, multivariable logistic regression was done to determine the independent effect of each factor and control confounding effect. A $p$-value $<0.05$ was used as cut of point to declare statistically significant. Multicollinearity was checked to see the correlation among independent variables. Model fitness was checked with Hosmer Lemshow test. Knowledge questions were categorized and coded as ( $\operatorname{good}=1$ and poor $=0)$ whereas attitude questions were categorized and coded as ( $1=$ Positive attitude and $0=$ Negative attitude). Cronbach alpha was checked to assure the internal consistency of attitude measuring questions.

\section{Results}

\section{Socio-demographic characteristics}

A total of 416 women participated in this study with a response rate of $95.4 \%$. The mean age of the participants was $23.23(\mathrm{SD} \pm 4.6)$ years with a predominant age group of $20-24$ years $(48.1 \%)$. The majority of the participants

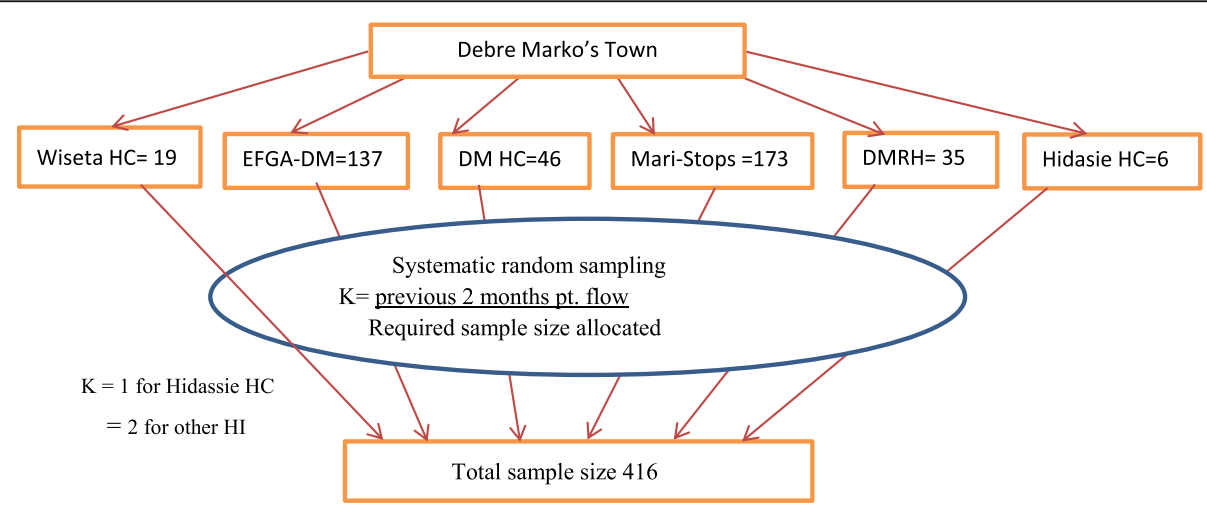

Fig. 1 Sampling procedures, Debre Marko's, Ethiopia, 2019 
were Orthodox religious followers (87.9\%) and urban residents (79.1\%). Most of the participants were not married (64.7\%) and completed secondary education (34.0\%) (Table 1).

\section{Obstetrics, sexual and reproductive characteristics}

The majorities of the participants have no living children $(76.1 \%)$ and were at first trimester with the current pregnancy (94.7\%). The majority of the participants had no sexual partner discussion about contraceptives (67.5\%) and they had no previous bad history of contraceptive utilization (79.1\%). Most of the participants were accessible for contraceptive service (95.2\%). The mean age of first sex was 18.3 years with $(\mathrm{SD} \pm 2.6)$ years (Table 2$)$.

\section{Knowledge and attitude about contraceptives}

More than half of the participants had good knowledge about contraceptives (55.4\%) and around half of the participants had a positive attitude for contraceptives (50.1\%) (Table 3).

Table 1 Socio-demographic characteristics of women seeking an induced abortion, Debre Marko's town, Ethiopia, 2019( $n=$ 397)

\begin{tabular}{|c|c|c|}
\hline Variables & Frequency & Percentage \\
\hline \multicolumn{3}{|l|}{ Age of participants } \\
\hline $15-19$ & 80 & 20.2 \\
\hline $20-24$ & 191 & 48.1 \\
\hline $25-29$ & 67 & 16.9 \\
\hline$>=30$ & 59 & 14.9 \\
\hline \multicolumn{3}{|l|}{ Residence } \\
\hline Urban & 314 & 79.1 \\
\hline Rural & 83 & 20.9 \\
\hline \multicolumn{3}{|l|}{ Religion } \\
\hline Orthodox & 349 & 87.9 \\
\hline Muslim & 25 & 6.3 \\
\hline Protestant & 18 & 4.5 \\
\hline Others & 5 & 1.3 \\
\hline \multicolumn{3}{|l|}{ Marital status } \\
\hline Married & 105 & 26.4 \\
\hline Unmarried & 257 & 64.7 \\
\hline Divorced/Widowed & 35 & 8.8 \\
\hline \multicolumn{3}{|l|}{ Educational status } \\
\hline No formal education & 56 & 14.1 \\
\hline Primary & 100 & 25.2 \\
\hline Secondary & 135 & 34.0 \\
\hline Tertiary \& above & 106 & 26.7 \\
\hline
\end{tabular}

Table 2 Sexual and Reproductive characteristics of women seeking an induced abortion, Debre Marko's town, Ethiopia, 2019 $(n=397)$

\begin{tabular}{lll}
\hline Variables & Frequency & Percentage \\
\hline $\begin{array}{l}\text { Number of living children } \\
0\end{array}$ & 302 & 76.1 \\
$>=1$ & 95 & 23.9 \\
Age of first sex & & \\
$<=14$ & 29 & 7.3 \\
15-19 & 219 & 55.2 \\
$>=20$ & 149 & 37.5 \\
Gestational age & & \\
1st trimester & 376 & 94.7 \\
2nd trimester & 19 & 4.8 \\
3rd trimester & 2 & 0.5 \\
Sexual partner discussion & & \\
No & 268 & 67.5 \\
Yes & 129 & 32.5 \\
Bad history of contraceptive utilization & \\
No & 314 & 79.1 \\
Yes & 83 & 20.9 \\
Accessibility of FP service & & 95.2 \\
No & 19 & \\
Yes & 378 & \\
\hline
\end{tabular}

\section{History of contraceptive use}

Among participants, 164(41.3\%) reported that they had used contraceptives within the last 6 months before their current pregnancy (Table 4). Among the participants, 9.1\% had pregnancy while using contraceptives (failure rate). Among contraceptive users, $65.9 \%$ of them used oral contraceptives, and $31.7 \%$ used injectable contraceptives (Fig. 2).

\section{Factors associated with the history of contraceptive use} In multivariable logistic regressions, participants' knowledge and attitude about contraceptives, number of living children, frequency of sexual practice, and having

Table 3 Knowledge and attitude about contraceptives of women seeking an induced abortion, Debre Marko's town, Ethiopia, 2019( $n=397)$

\begin{tabular}{lll}
\hline Variables & Frequency & Percentage \\
\hline Knowledge about contraceptives & & \\
Poor knowledge & 220 & 55.4 \\
Good knowledge & 177 & 44.6 \\
Attitude for contraceptives & & \\
Negative attitude & 198 & 49.9 \\
Positive attitude & 199 & 50.1 \\
\hline
\end{tabular}


Table 4 Prevalence history of contraceptive use among women seeking an induced abortion, Debre Marko's town, Ethiopia, 2019

\begin{tabular}{lcc}
\hline & Frequency & Percentage \\
\hline History of contraceptive Use & \\
No & 233 & $58.7(53.9-63.5)$ \\
Yes & 164 & $41.3(36.5-46.1)$ \\
Contraceptive use at the time of Conception (failure rate) \\
No & 361 & 90.9 \\
Yes & 36 & 9.1 \\
Intention to Post abortion contraceptive utilization \\
No & 28 & 7.1 \\
Yes & 369 & 92.9 \\
\hline
\end{tabular}

discussions with sexual partners about contraceptives were found significantly associated with contraceptive use. The odds of contraceptive use among women who had good knowledge about contraceptive were 3.9 times (95\%CI: 2.360, 6.548) higher compared to their counterpart. The odds of contraceptive use among women who had a positive attitude about contraceptives were 1.6 times (95\%CI: 1.023, 2.561) higher compared to women who had a negative attitude.

Women who had living children were 2.1 times (95\% CI; 1.040, 4.112) higher the odds of contraceptive use compared to those who had no children. The odds of contraceptive use among women who had frequent sexual practice were 2.5 times (95\% CI; $1.538,4.213)$ higher compared to women who had an infrequent sexual practice. Lastly, women who had a discussion on contraceptives with their sexual partners were found 1.9 times (95\% CI: 1.185, 3.181) higher odds of contraceptive use than their counterparts (Table 5).
Study participants reported that unplanned sex was the main reason for not using contraceptives before their current pregnancy. About 51.9\% of the participants reported that their pregnancy was due to unplanned sex. The study also showed that the other reason for none contraceptive use before the current pregnancy was not expecting the occurrence of pregnancy (38.6\%). The majority of the participants also raised hormonal side effects of the contraceptives as their reason for none contraceptive use (Fig. 3).

\section{Discussion}

The result of this study revealed that only $41.3 \%$ (95\%CI: 36.5-46.1) of abortion seeker women were utilized contraceptives within the last 6 months before their index pregnancy. Even though the women had access to contraceptives, they didn't use a contraceptive to prevent their unplanned pregnancy which leads them to abortion-related problems and needs a high national cost for abortion service.

This finding is lower than the studies done in Addis Ababa (56.6\%) and Hawassa (66\%) among women seeking an induced abortion. The possible reasons may be due to the time variation of contraceptive use before the index pregnancy and the frequency of abortion. For example, in the current study shows contraceptive use within the last 6 months before the index pregnancy, regardless of the frequency of abortion, whereas the studies done in Addis Ababa and Hawassa reported ever use of contraceptives before the index pregnancy. Moreover repeated abortion seeking women who had more likely to use contraceptives who were included in Addis Ababa study's [11, 12].

Similarly, the result of this study is lower than the studies done in India (59.1\%), Iran (63.5\%) and Yorkshire (US) (69\%). The possible reasons may be due to those

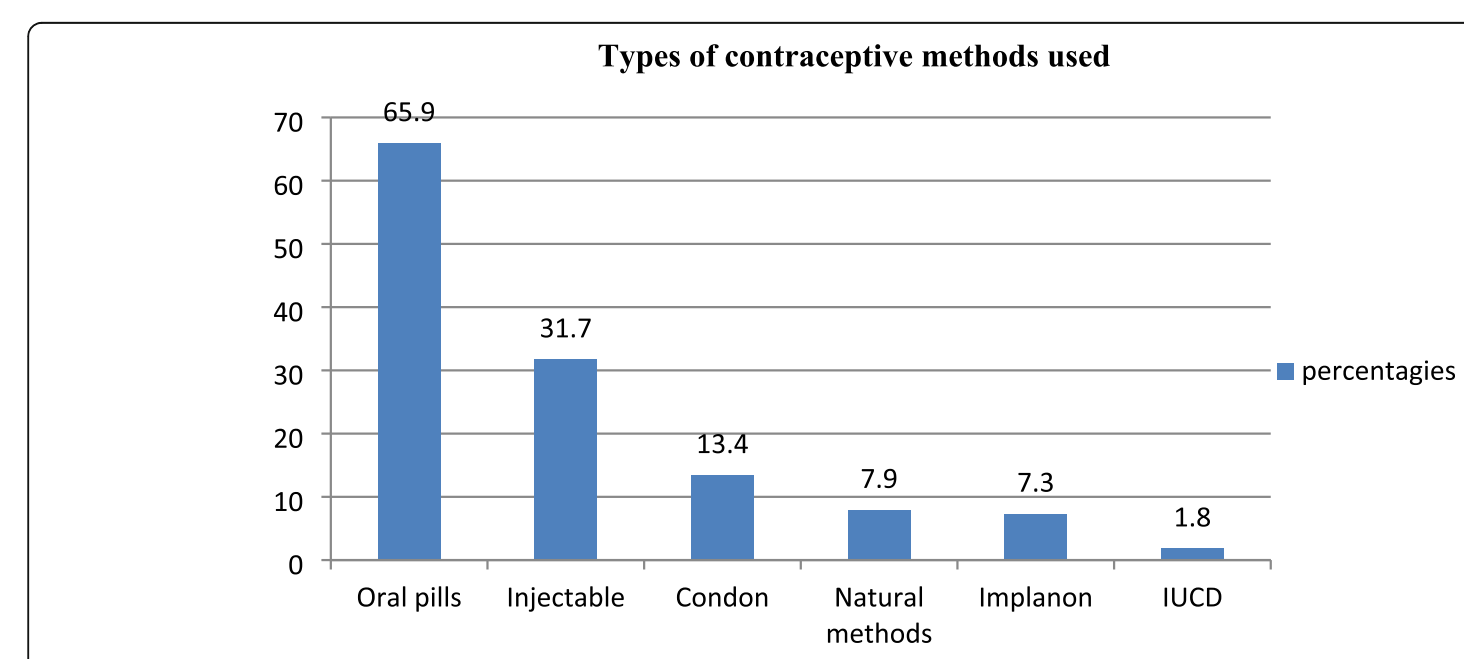

Fig. 2 Types of contraceptive used among abortion seeking women in Debre Marko's town, Ethiopia, 2019( $n=164)$ 
Table 5 Bivariate \& multivariable regression of women seeking an induced abortion, Debre Marko's town, Ethiopia, 2019(n = 397)

\begin{tabular}{|c|c|c|c|c|c|}
\hline & \multicolumn{2}{|c|}{ Contraceptive utilization } & \multirow[t]{2}{*}{ COR(95\%Cl) } & \multirow[t]{2}{*}{ AOR $(95 \% \mathrm{Cl})$} & \multirow{2}{*}{$\begin{array}{l}\text { P- } \\
\text { value }\end{array}$} \\
\hline & No & Yes & & & \\
\hline Age & & & & & .113 \\
\hline $15-19$ & 52 & 28 & 1 & 1 & \\
\hline $20-24$ & 109 & 82 & $1.397(.813,2.401)$ & $.682(.363,1.282)$ & .237 \\
\hline $25-29$ & 35 & 32 & $1.698(.874,3.298)$ & $.592(.260,1.347)$ & .224 \\
\hline$\geq 30$ & 37 & 22 & $1.104(.549,2.223)$ & $.294(.110, .782)$ & .015 \\
\hline \multicolumn{6}{|l|}{ Marital status } \\
\hline Married & 40 & 65 & $3.545(1.569,8.011)$ & $1.860(.704,4.917)$ & .211 \\
\hline Unmarriec & 169 & 88 & $1.136(.532,2.426)$ & $1.127(.428,2.963)$ & .809 \\
\hline Divorced & 24 & 11 & 1 & 1 & \\
\hline \multicolumn{6}{|c|}{ Number of living children } \\
\hline 0 & 117 & 185 & 1 & 1 & \\
\hline$\geq 1$ & 47 & 48 & $1.548(.973,2.463)$ & $2.068(1.040,4.112)$ & .04 \\
\hline \multicolumn{6}{|l|}{ Knowledge } \\
\hline Poor & 36 & 134 & 1 & 1 & \\
\hline Good & 128 & 99 & $4.813(3.063,7.562$ & $3.931(2.360,6.548)$ & .000 \\
\hline \multicolumn{6}{|l|}{ Attitude } \\
\hline Negative & 67 & 131 & 1 & 1 & \\
\hline Positive & 97 & 102 & $1.859(1.240,2.787)$ & $1.619(1.023,2.561)$ & .041 \\
\hline \multicolumn{6}{|c|}{ Sexual partner discussion } \\
\hline No & 86 & 182 & 1 & 1 & \\
\hline Yes & 78 & 51 & $3.237(2.092,5.007)$ & $1.941(1.185,3.181)$ & .009 \\
\hline \multicolumn{6}{|c|}{ Frequency of sexual practice } \\
\hline Infrequent & 192 & 92 & 1 & 1 & \\
\hline Frequent & 41 & 72 & $3.665(2.321,5.788)$ & $2.545(1.538,4.213)$ & .000 \\
\hline \multicolumn{6}{|l|}{ Residence } \\
\hline urban & 170 & 144 & $2.668(1.540,4.624)$ & $1.51(0.807,2.836)$ & .019 \\
\hline Rural & 63 & 20 & 1 & 1 & \\
\hline
\end{tabular}

Variable(s) entered on step 1: SPAge, Residenc, MaritalStat, Educational status, Number of living children, Frequency of sexual practice, Knowledge, Attitude, History of abortion, Disscussion with sexual partner, Accessibilty, Bad history of Contraceptive utilization

studies show ever uses of contraceptives before the current pregnancy. This implies that a woman may have higher contraceptive utilization experience before the index pregnancy regardless of the time-bound [13-15].

This finding is in line with the study done in China, which shows $38 \%$ of the participants who received abortion service were utilizing any contraceptive during the 6 months preceding the survey [16]. The current result also supported by the study done in Missouri(US) and Cape Town (South Africa) as they revealed that 37 and $44.1 \%$ of the study participants reported utilized contraceptives before the current pregnancy respectively $[17,18]$.

On the contrary, the current finding is higher than the studies done in Bangalore and Pakistan, which reported that 35.7 and $27 \%$ of the participants had contraceptive use experience before the index pregnancy respectively.
This variation may be due to participant's contraceptives knowledge difference since 23.8\% in Bangalore and 17\% in Pakistan lacking awareness on any contraceptive methods as lack of knowledge is the biggest hurdle the practice of contraceptives. There was also in-laws opposition to use contraceptives in Pakistan since $22 \%$ of women raised it for the reason of none contraceptive use $[19,20]$.

The finding of the current study revealed that women who had living children were increase the odds of contraceptive use compared to those women had no living children which is consistent with the study done in North Showa Zone, Ethiopia. The possible explanation could be due to the fact that women who had living children might have a lower future fertility desire and their intention to use contraceptive methods might be high [21]. The finding of this result is also in line with the 


\section{Reasons for not utilizing contraceptives}

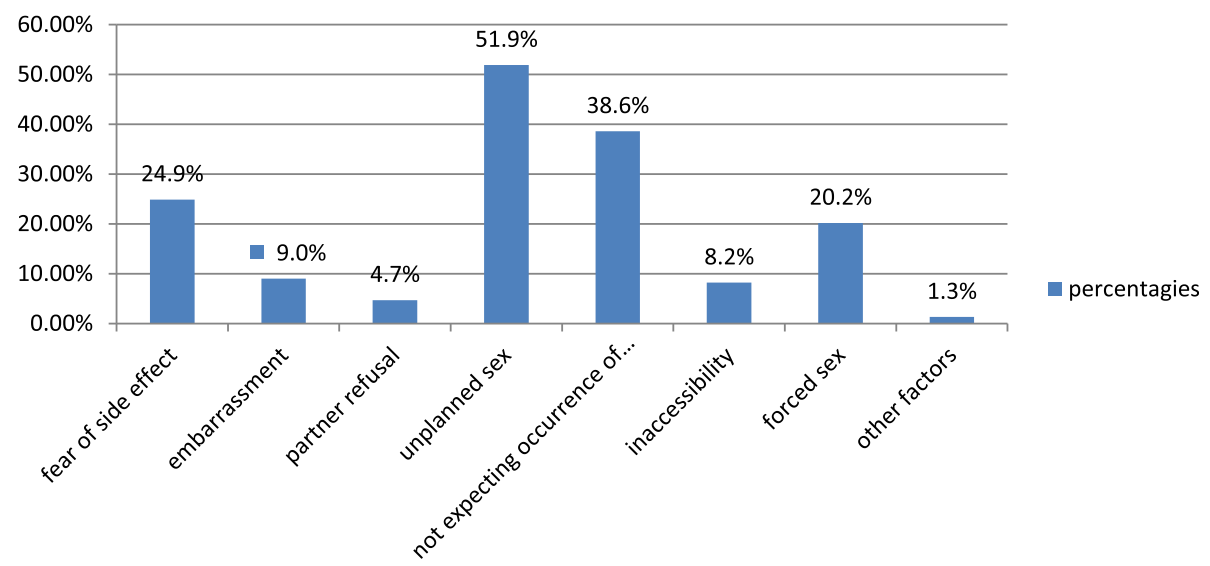

Fig. 3 Reasons for not using contraceptives among women seeking induced abortion, Debre Marko's town, Ethiopia, 2019( $n=233)$

study done in Western Cape (South Africa), which revealed that women who have living children were more likely to use contraceptive due to less chance of sexual practice since they may be unmarried (58). This finding is similar to previous reports from Bangladesh and Tanzania which reported that as the number of living children increases, the use of modern contraceptives increases [22, 23].

Contraceptive use among women seeking abortion who have frequent sexual practice had more likely than women who had an infrequent sexual practice. The possible reason may be related to the perception of women who had reduced sexual exposure and reduced fecundity could have low risk of pregnancy and lead them use of contraceptive is unnecessary [24].

The finding of this study showed that women who had good knowledge about contraceptive was one of the predictors of contraceptives use which is consistent with the studies done in Ethiopia; Dabat [25], Fogera [26] and abroad Sweden [27]. It is evident that lack of basic knowledge on contraceptive is the biggest hurdle in the practice of contraceptives [28].

Women who have a positive attitude about contraceptives had a better contraceptive history than women who have a negative contraceptive attitude which is supported by the studies done in different parts of Ethiopia as it showed women who had a favorable attitude towards FP were more likely to practice contraceptives [29].

In this study, women who had a discussion with their sexual partner about contraceptives had a better use of contraceptive history, which is consistent with other studies done in Bahir Dar and North Showa, Ethiopia. These studies revealed that women who had a discussion on contraceptive methods with sexual partner were more likely utilize contraceptives since male involvement encouraged their sexual partners to use contraceptives regularly $[21,30]$.

This study has its own limitations. Social desirability bias is one of the limitations of this study since women may report more acceptable response. Recall bias might be also occurred since women may forget the exact their current pregnancy time of conception. This study did not establish cause and effect relationship between independent and outcome variable due to the limitation of cross-sectional study design.

\section{Conclusions}

Contraceptive use among women seeking an induced abortion was low despite the expected national goal of $55 \%$ contraceptive use in 2020. Women's marital status, knowledge about contraceptives, and sexual partner discussion of contraceptives were significantly increasing the use of contraceptives.

The identified factors help to strengthen the existing country's strategies to focus on abortion seeking women to decrease the rapid increment of abortion practice and its related health and economic burden. Adequate information and instructions on contraceptive methods should be given for the users to improve women's contraceptive knowledge. Women and their sexual partner should be encouraged to discuss on importance of contraceptive use to improve joint partner collective decision-making. In this study, contraceptive failure was also occurred among majority of women who used emergency contraceptive which could be an area of further research.

\section{Abbreviations}

AOR: Adjusted odds ratio; Cl: Confidence interval; COR: Crude odds ratio; FP: Family planning; HSTP: Health sector transformation plan; NGO: None Governmental Organization; SD: Standard deviation; SNNP: South Nation 
Nationality and People; SPSS: Statistical package for the social sciences; USA: the United States of America; WHO: World Health Organization

\section{Acknowledgments}

The authors would like to acknowledge Debre Marko's town health department and respective offices for their permission to conduct this study. Similarly, we would like to acknowledge our data collectors and study participants for their active participation in the production of this study.

\section{Authors' contributions}

All authors were equally contributed to the production of this manuscript. The author(s) read and approved the final manuscript.

\section{Funding}

No funding received for this specific study.

\section{Availability of data and materials}

The datasets used and/or analyzed during the current study are available from the corresponding author on reasonable request.

\section{Ethics approval and consent to participate}

The ethical clearance was obtained from IRB of Bahir Dar University, College of Medicine and Health Sciences with a protocol number of the letter 02012/18-09. A formal letter was given to the selected health institutions from the school of public health. Moreover, informed consent was obtained from each respondent and aware of them their right to withdraw from the study at any time. Written informed consent was obtained from a parent or guardian for participants under 16 years old. The information given by each respondent was kept confidential since the dissemination of the finding was not be referring to specific respondents but to the general source population and the data was collected with referring the study participants' names, and the data was not exposed for any third body.

\section{Consent for publication}

Not applicable.

\section{Competing interests}

The authors declare that they have no competing interests.

\section{Author details}

${ }^{1}$ Department of Midwifery, College of Health Sciences, Woldia University, Woldia, Ethiopia. ${ }^{2}$ Department of Health Service Management and Health Economics, School of Public Health, Bahir Dar University, Bahir Dar, Ethiopia. ${ }^{3}$ Department of Environmental Health, School of Public Health, Bahir Dar University, Bahir Dar, Ethiopia.

Received: 3 November 2019 Accepted: 10 June 2020

\section{Published online: 17 June 2020}

\section{References}

1. World health organization (WHO). Family planning in health services: report of a WHO expert committee [meeting held in Geneva from 24 to 30 November 1970]. 1971.

2. World health organization (WHO). Family planning/contraception: fact sheet No 351 2015. Available from: Available from: [Last accessed on 2016 Dec 26]. Back to cited text, 2017).

3. World health organization (WHO). World Family Planning. 2017 Contract No.: ST/ESA/SER.A/414

4. Sundaram A, Vlassoff M, Bankole A, Remez L, Gebrehiwot Y. Benefits of meeting the contraceptive needs of Ethiopian women. Alan Guttmacher Inst. 2010;1:1-8.

5. Blumenthal PD, Voedisch A, Gemzell-Danielsson K. Strategies to prevent unintended pregnancy: increasing use of long-acting reversible contraception. Hum Reprod Update. 2010;17(1):121-37.

6. Moore A, Gebrehiwot Y, Fetters T, Wado Y, Bankole A, Singh S, et al. The estimated incidence of induced abortion in Ethiopia, 2014: changes in the provision of services since 2008. Int Perspect Sex Reprod Health. 2016;42(3):111.

7. Ethiopian public health institute (EPHI). Induced Abortion and Postabortion Care in Ethiopia. Addis Ababa: EPHA; 2017.
8. Deschener A., Cohen S. Contraceptive use is key to reducing abortion worldwide. USA: Guttmacher Institute; 2003.

9. Singh S, Fetters T, Gebreselassie H, Abdella A, Gebrehiwot Y, Kumbi S, et al. The estimated incidence of induced abortion in Ethiopia. Int Perspect Sex Reprod Health. 2008;2010:16-25.

10. Bertrand J, Magnani R, Rutenberg N. Handbook of indicators for family planning program evaluation; 1994.

11. Prata N., Holston M., Fraser A., Melkamu Y. Contraceptive use among women seeking repeat abortion in Addis Ababa, Ethiopia. African journal of reproductive health. 2013;17(4):5-6.

12. Tafesse L, Hussen M, T T. The Contraceptive Knowledge, Practices and Reasons for Failure among Abortion Care Seekers in Hawassa City, Ethiopia. Journal of Biology, Agriculture and Healthcare. 2014;4(25):55-6.

13. Bexhell H, Guthrie K, Cleland K, Trussell J. Unplanned pregnancy and contraceptive use in Hull and East Yorkshire. Contraception. 2016:93(3):233-5.

14. Bayrami R., Javadnoori M. Comparison of the contraceptive use and its related factors among women seeking repeat and first-time induced abortions in Iran. Nursing and midwifery studies. 2015;4(1):4.

15. Perslev A, Rørbye C, Boesen H, Nørgaard M, Nilas L. Emergency contraception: knowledge and use among Danish women requesting termination of pregnancy. Contraception. 2002;66(6):427-31.

16. Liu J, Wu S, Xu J, Temmerman M, Zhang W-H, Group I. Is repeat abortion a public health problem among Chinese adolescents? A cross-sectional survey in 30 provinces. Int J Environ Res Public Health. 2019;16(5):794.

17. Homco J, Peipert J, Secura G, Lewis V, Allsworth J. Reasons for ineffective pre-pregnancy contraception use in patients seeking abortion services. Contraception. 2009;80(6):569-74.

18. Oluwole E, Skaal L. Contraceptive practices among women seeking termination of pregnancy in one public hospital in eastern cape, South Africa. Afr J Prim Health Care Fam Med. 2016;8(1):1-6.

19. Nataraja H., Harshini V. Contraceptive Knowledge Attitude and Practice (KAP) among Women who were seeking for Termination of Pregnancy. Asian Journal of Biomedical and Pharmaceutical Sciences. 2013;3(23):4.

20. Afridi F, Qazi Q, Gulab N. Contraceptive awareness \& use among women seeking termination of pregnancy. J Med Sci. 2014;22(4):201-4.

21. Mohammed A, Woldeyohannes D, Feleke A, Megabiaw B. Determinants of modern contraceptive utilization among married women of reproductive age group in north Shoa zone, Amhara region, Ethiopia. Reprod Health. 2014;11(1):13.

22. Mostafa Kamal S, Aynul IM. Contraceptive use: socioeconomic correlates and method choices in rural Bangladesh. Asia Pac J Public Health. 2010;22(4):436-50.

23. Lwelamira J, Mnyamagola G, Msaki M. Knowledge, attitude and practice (KAP) towards modern contraceptives among married women of reproductive age in Mpwapwa District, Central Tanzania. Curr Res J Soc Sci. 2012;4(3):235-45.

24. OlaOlorun FM, Hindin MJ. Having a say matters: influence of decisionmaking power on contraceptive use among Nigerian women ages 35-49 years. PLoS One. 2014;9(6):e98702.

25. Alemay T, Fekadu A, Yitayal M, Kebede Y, Abebe S, Ayele T, et al. Prevalence and determinants of contraceptive utilization among married women at Dabat health and demographic surveillance system site, Northwest Ethiopia. BMC Womens Health. 2018;18(1):118.

26. Kassa T, Degu G, Birhanu Z. Assessment of modern contraceptive practice and associated factors among currently married women age 15-49 years in Farta District, South Gondar zone, north West Ethiopia. Sci J Public Health. 2014;2(6):507-12.

27. Larsson M, Aneblom G, Odlind V, Tydén T. Reasons for pregnancy termination, contraceptive habits and contraceptive failure among Swedish women requesting an early pregnancy termination. Acta Obstet Gynecol Scand. 2002:81(1):64-71.

28. Kathpalia S. Emergency contraception: Knowledge and practice among women and the spouses seeking termination of pregnancy. Med J Armed Forces India. 2016;72(2):116-9.

29. Kasa AS, Tarekegn M, Embiale N. Knowledge, attitude and practice towards family planning among reproductive age women in a resource limited settings of Northwest Ethiopia. BMC Res Notes. 2018;11(1):577.

30. Tesfa E, Gedamu H. Factors associated with utilization of long term family planning methods among women of reproductive age attending Bahir Dar health facilities, Northwest Ethiopia. BMC Res Notes. 2018;11(1):926.

\section{Publisher's Note}

Springer Nature remains neutral with regard to jurisdictional claims in published maps and institutional affiliations. 